\title{
Index of Matters
}

Artificial Intelligence $175,177 \mathrm{f}$.

Book Prose Theory 82, 266

Conjointure 25

Discourse Analysis 43

Distributed Author 79-81, 175, 188f.

Distributed Object 188

Distributed Representation 80,189

Free Prose Theory 82, 266

Hermeneutics 14

Icelandic School 14, 17, 20, 34-38, 40f., 143, 266, 284

Immanent Whole Concept $82-84,93$
Material Philology 10, 40, 46

Material Turn 40

Mouvance $10 \mathrm{f} ., 14,75,78,80,86 f ., 92 f ., 142,158$, $171,245,248$

Multiform 188

New Philology 10, 40, 46, 64, 142

Postmodernism 58, 171, 177

Post-structuralism 43

Rhizome 17, 44, 75, 83-87, 92 f.

Runic Inscriptions / Runic Writing 28, $60 \mathrm{f}$.

Structuralism 43

páttr Theory 81

Variance $10-14,40,75,77,80,84,86 f$., 92, 142, $167,171,245,248$ 
